\title{
Bio-fabrication of thermozyme-based nano-biosensors: their components and present scenario
}

\author{
Snehi Soy ${ }^{1}$, Shubha Rani Sharma ${ }^{1}$, and Vinod Kumar Nigam ${ }^{1, *}$ (D) \\ ${ }^{1}$ Department of Bioengineering and Biotechnology, Birla Institute of Technology, Mesra, Ranchi, Jharkhand 835215, India
}

Received: 1 July 2021

Accepted: 6 January 2022

Published online:

29 January 2022

(C) The Author(s), under exclusive licence to Springer Science+Business Media, LLC, part of Springer Nature 2022

\begin{abstract}
An amalgamation of microbiology, biocatalysis, recombinant molecular biology, and nanotechnology is crucial for groundbreaking innovation in developing nano-biomedicines and sensoristics. Enzyme-based nano-biosensor finds prospective applications in various sectors (environmental, pharmaceutical, food, biorefineries). These applications demand reliable catalytic efficiency and functionality of the enzyme under an extreme operational environment for a prolonged period. Over the last few years, bio-fabrication of nano-biosensors in conjunction with thermozymes from thermophilic microbes is being sought after as a viable design. Thermozymes are known for their robustness, are chemically resistant toward organic solvents, possess higher durability for constant use, catalytic ability, and stability at elevated temperatures. Additionally, several other attributes of thermozymes like substrate specificity, selectivity, and sensitivity make them desirable in developing a customized biosensor. In this review, crucial designing aspects of enzyme-based nano-biosensors like enzyme immobilization on an electrode surface, new materials derived from microbial sources (biopolymers based nanocomposites), improvisation measures for sensitivity, and selectivity have been addressed. It also covers microbial biosynthesis of nanomaterials used to develop sensoristic devices and its numerous applications such as wastewater treatment, biorefineries, and diagnostics. The knowledge will pave the way toward creating consistent eco-friendly, economically viable nanostructured-based technologies with broad applicability and exploitation for industrial use in the near future.
\end{abstract}

\section{Introduction}

Biosensors are outstanding examples of interdisciplinary applied research with diverse applications. The advent of biosensors' research dates back to 1962 when the first-generation glucose oxidase (GOx) biosensor was introduced by Clark and Lyons [1, 2]. At present, remarkable growth in the global biosensors market has been observed and the market size is estimated to attain USD 23.7 billion by 2022, growing at a compound annual rate of $9.7 \%$ [3]. Biosensors have already established their niche in diagnostics,

Address correspondence to E-mail: vknigam@bitmesra.ac.in 
environmental pollutants monitoring, defense, biomedicine, and industries [4]. However, in the wake of consecutive pandemics in the last 15 years, especially considering the current global pandemic situation of COVID-19, constant demands for point-of-care technologies for rapid detection and characterization of pathogens [5] and pressing demands for a disposable, user and environmentally friendly, cost-effective devices is likely to propel the market for biosensors.

A biosensor exploits molecular recognition elements (MREs) such as whole cells, enzymes, antibodies, aptamers, tissues, etc. Among the biomolecules, enzymes are mostly preferred because of their inherent property of catalyzing reactions with high selectivity, specificity, and efficiency, which are significant parameters for designing enzyme-based biosensors [6]. However, enzyme stability has always been of prime concern in applications demanding the durable use of biosensors. Specific processes that require high temperature causes protein denaturation, resulting in reduced catalytic activity; hence decreased functional potential of the sensor has been reported [7]. Therefore, robust thermozymes with desirable properties are paving the way for the fabrication of stable biosensors.

Further, integration of nanomaterials as a transducer or immobilizing materials in biosensor design has exhibited remarkable improvement in biosensor sensitivity, stability, the limit of detection (LOD), selectivity, response rate, and other analytical characteristics [8], such as graphene-based nanomaterials that not only served as an efficient enzyme immobilizing material but significantly improved enzyme activity and thermostability [7] thus emphasizing its potential as a critical component in sensoristics design.

It is well known that the analytical performance of enzyme-based biosensors is majorly governed by enzyme uniqueness, immobilization method, and electrode features [9]. Therefore, there is a need to combine both thermozymes and nanomaterials for the fabrication of thermozyme-based nano-biosensor. The blend of bio/nanomaterials, nanoparticles, and thermozymes with their distinct striking properties can be vital for miniaturization and the upgradation of existing nano-biosensor to the high-throughput sensing device.

Thus, the review highlights those aspects of biosensor fabrication, which have exhibited promising results, but need further exploration. In particular, insubstantial research on biosensing concepts that have combined the thermostable biocatalysts with nanomaterials has been presented, along with the limitations that obstructed its usage.

\section{Bio-fabrication of thermozyme-based nano-biosensors: essential components}

The design of an efficient enzyme-based biosensor demands several key players, namely, biosensing molecules, immobilization techniques, immobilizing materials, accurate transducer, and packaging, to ensure its portability [10]. Among all key players, immobilization substance (nano/biomaterial) and the biocomponent (thermostable enzyme) are of prime focus here.

\subsection{Thermozymes as MREs}

Despite technological advancements, it is still a roadblock to design and synthesize organic molecules with the specific binding ability for structurally complex analytes [11]. Moreover, even if synthesis is possible, it cannot be assured that structural changes functional for sensing will occur upon interaction with the target analyte. Hence, to impede these limitations, modern biotechnology has retreated to the idea of using proteins and enzymes as functional sensing biocomponents.

There are several industrial and commercial applications where naturally occurring enzymes pose restrictions owing to their limited stability and activity under extreme working conditions. The tedious downstream processing of enzymes and obtainment from other eukaryotic systems adds to expensive disposable biosensors [9]. Therefore, the quest for novel enzymes with potential biotechnological applications has led to mining enzymes from extremophiles and improvising the properties via recombinant or protein engineering strategies [12]. Thermozymes possess remarkable properties such as high thermostability, substrate selectivity, and elevated enzymatic activity [13-15]. They are not prone to proteolysis and chemical denaturation in the presence of detergents, extreme $\mathrm{pH}$, chaotropic agents, and organic solvents [16-18]. Thermozymes can retain native protein structure and function at extreme temperatures because the protein is highly stabilized. This stability attribute results from several 
factors, such as the balance between flexibility and rigidity due to their amino acid composition. The thermostable protein amino acid composition has higher levels of alanine, isoleucine, proline, and valine because of which they have compact packaging of hydrophobic cores, and the loops are more stable, resulting in more contact surface area $[19,20]$. Also, lower levels of amino acids, namely, asparagine, cysteine, glutamine, methionine, and tryptophan, minimizes the risk of deamidation and oxidation at high temperatures [6, 21].

Thermozymes potential as MREs in biosensing application is attributed to their stability, longer shelf life, and catalytic activity in the presence of organic solvents [22]. One of the obvious reasons is that there are different analytes in the sample with the organic solvent requirement as cosolvent due to low solubility in aqueous media. Additionally, most of the analytes used in biosensors are only soluble at high temperatures [23].

Several enzymes from thermophiles have been used for developing stable and sensitive biosensors/nano-biosensors. Some of the developments in the past 20 years have been listed in Table 1 .

\subsection{Nano/Biomaterials: bio-fabrication potential in sensing applications}

Nanomaterials are prospective materials and have excellent attributes that can be employed to improvise electrochemical, mechanical, magnetic, optical properties, and development of single-molecule (biomolecules and nanomaterials combo) nanobiosensors with high-throughput biosensor arrays [4]. Incorporating nanomaterials as a versatile supporting medium for immobilizing enzymes has garnered much interest in the biotechnology community. These robust nanostructures, namely, carbon nanotubes (CNTs), quantum dots (QDs), nanofibres, nanosheets, nanowires, metal nanoparticles (MNPs), nanopores, nanocomposites, self-adhesive monolayers, graphene, are ideal materials for the fabrication of novel nano-biosensor [24, 25]. They have a nanodimension and high electrical and thermal conductivity, which plays a role in imparting sensitivity and specificity to the nanosensors. They have a high surface area to volume ratios, thus enabling elevated enzyme loading compared to macroscopic $2 \mathrm{D}$ interfaces and enhanced reaction kinetics due to gain in catalytic strength $[9,26]$. It ultimately leads to significant output concerning biocatalytic efficiency for numerous applications. Additionally, immobilization on nanomaterials also influences the enzyme's substrate selectivity and stability [27], broadens the operating temperature and $\mathrm{pH}$ range, and enhances thermostability [28], and also immobilized system can operate in both aqueous and non-aqueous media [29]. Additionally, nanoparticle-based immobilization has several advantages over conventional immobilization methods, such as easy synthesis of nano-enzyme particles in highly reliable content, no use of hazardous toxic surfactants and chemicals, and convenient tailoring of particle size based on utility. Furthermore, co-immobilization of multi-enzymes on nanoparticles with the help of in vitro synthetic biology for cascade multi-enzyme reaction can be achieved [28].

As mentioned in the earlier section, thermozymes are an exquisite class of biomolecules with inherent thermostability and robustness under extreme environments. Certain kinds of nanoparticles (chemical/ biological origin) can be incorporated to augment further their stability, selectivity, sensitivity, and robustness. Some of the noteworthy examples where enzymes from thermophile sources were used in combination with nanomaterial and significant output on stability and activity were obtained and tabulated (Table 2).

\subsection{Nanobiosensors}

Nanobiosensors are biosensors which integrate nanostructures; however, they are more versatile and have far better advantage over biosensors. The nanostructure encapsulation of biological analytes offers extensive array of sample stabilization and, thus, has high sensitivity. The miniaturization of biosensors due to nanostructures and requirement of a small sample size gives the possibility to design biochips. It is for the very same reason nano-biosensors are constantly emerging and finding usage in diagnostics applications. The combination of nanostructures and electrochemical techniques has improvised the efficiency, sensitivity, response time, and the decomposition power of the sensor, thus paving way toward rapid and cost-effective assay of variable analytes. Electrochemical nano-biosensors have metal nanostructures that increase the surface area of the receptor, thus profoundly enhancing the sensor's sensitivity. The metal nanostructures have 


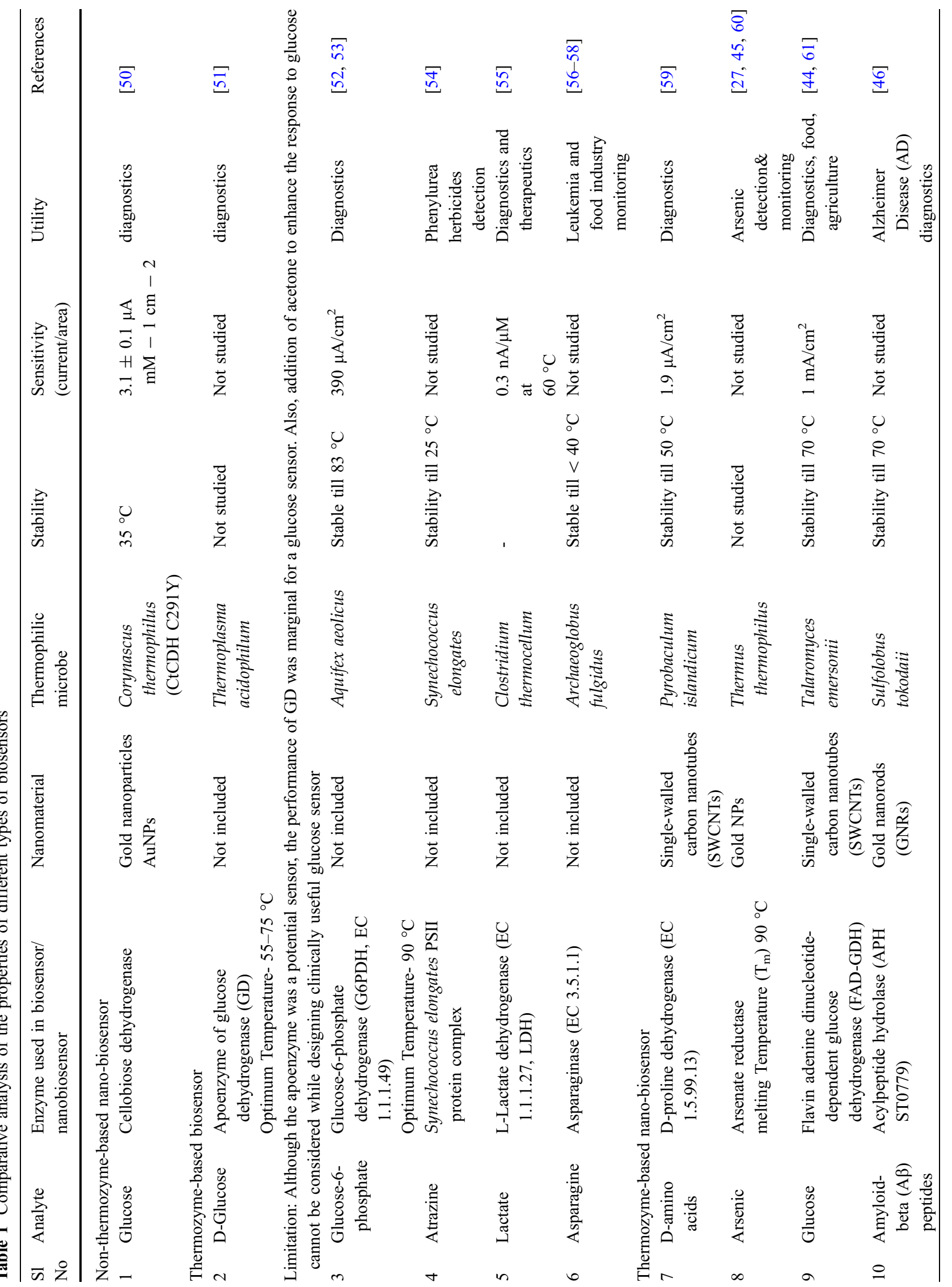


Table 2 Nanomaterials/nanoparticles impact on industrially important enzymes from extremophiles for properties enhancement

\begin{tabular}{|c|c|c|c|c|c|}
\hline $\begin{array}{l}\text { S1 } \\
\text { No }\end{array}$ & Enzyme & Source & Nanomaterial & Output & References \\
\hline 1 & Laccase & $\begin{array}{l}\text { P. putida } \\
\text { AKPSYL } \\
\text { (psychrophile) }\end{array}$ & $\begin{array}{l}\text { Supplemented with copper } \\
\text { oxide nanoparticles (NP) } \\
\text { Entrapped in single-walled } \\
\text { nanotubes (SWNT) }\end{array}$ & $\begin{array}{l}\text { Psychrostability }\left(4{ }^{\circ} \mathrm{C}\right) \\
\text { Thermostability }\left(80^{\circ} \mathrm{C}\right)\end{array}$ & {$[62]$} \\
\hline 2 & Glucokinase & $\begin{array}{l}\text { Aeropyrum } \\
\text { pernix }\end{array}$ & $\begin{array}{l}\text { Immobilized on AuNPs and } \\
\text { encapsulated in calcium } \\
\text { alginate }\end{array}$ & $\begin{array}{l}60 \% \text { enhanced activity when } \\
\text { subjected to photothermal } \\
\text { activation }\end{array}$ & {$[63]$} \\
\hline 3 & Impaired pectate lyase & $\begin{array}{l}\text { attenuated } \\
\text { Macrophomina } \\
\text { phaseolina }\end{array}$ & Hydroxyapatite nanoparticles & $\begin{array}{l}\text { Enhanced thermostability } \\
27.7 \text { fold increase in enzyme } \\
\text { activity with a } 51 \text { fold increase in } \\
\text { half-life at } 90^{\circ} \mathrm{C}\end{array}$ & {$[64]$} \\
\hline 4 & CotA laccase & B. subtilis & $\begin{array}{l}\text { Magnetic graphene oxide } \\
\text { modified with } \\
\text { nitrilotriacetic acid and } \mathrm{Cu}\end{array}$ & $\begin{array}{l}\text { Efficient decolorization at } \mathrm{pH} 8 \text {, } \\
60{ }^{\circ} \mathrm{C} \\
\text { Reusable after } 10 \text { cycles of usage }\end{array}$ & {$[65]$} \\
\hline 5 & $\begin{array}{l}\text { Coimmobilized O2-tolerant } \\
\text { hydrogenase and bilirubin } \\
\text { oxidase }\end{array}$ & Aquifex aeolicus & Carbon nanofibers & $\begin{array}{l}\text { Biofuel cell operated and delivered } \\
\text { electricity in } 30^{\circ} \mathrm{C}-80^{\circ} \mathrm{C} \text { range }\end{array}$ & {$[66,67]$} \\
\hline 6 & Laccase & $\begin{array}{l}\text { Pycnoporuss } \\
\text { anguineus } \\
\text { CS43 }\end{array}$ & $\begin{array}{l}\text { Anthracene-modified } \\
\text { multiwalled carbon } \\
\text { nanotubes }\end{array}$ & $\begin{array}{l}\text { Generated highly } \\
\text { thermostable bioelectrodes } \\
\text { Increased resistance to inhibitors } \\
\text { Produced elevated current densities }\end{array}$ & {$[67]$} \\
\hline
\end{tabular}

remarkable electrocatalytic effect that helps in the quick transfer of electrons. Rapid electron transfer results in enhanced efficiency by reducing the response time of nano-bio sensors, thus facilitating detection even at femtomolar and single-molecule levels [30]. The fabrication and sensing application of the Horseradish Peroxidase (HRP)-based enzyme biosensor to detect hydrogen peroxide has been represented in the figure (Fig. 1).

Another emerging field of nano-biosensors is cantilever-based nano-biosensors; cantilevers are rectangular bars of silicon with one micrometer of thickness functionalized with receptor molecules. These receptor molecules work on the deflection of

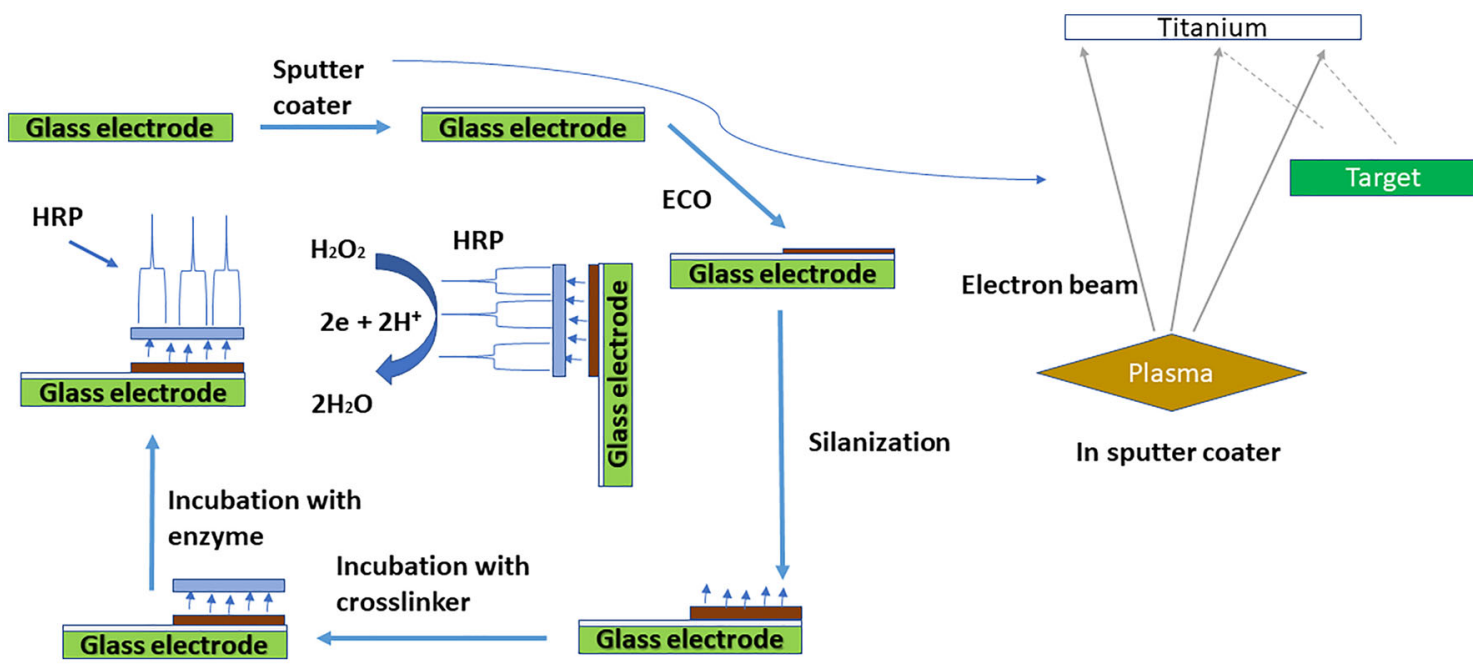

Fig. 1 Representation of bio-fabrication and sensing of HRP-based biosensor for detection of Hydrogen Peroxide (Prakash et al. 2015) 
laser beams. These are used for various rigorous environments such as standard atmospheric pressure, under vacuum conditions, high temperatures [31]; however, reported much earlier, the cantileverbased biosensors have come into focus in recent times. Enzyme-based cantilever sensors are also developed using self-assembling monolayers of the enzyme. These are sensitive to nano-scale measurements and are also robust to use.

Rigo and co-workers developed a urease-based cantilever biosensor to detect heavy metals in the river and drinking water samples to the minimal concentrations in parts per billion (ppb). The deflections were studied using an atomic force microscope (AFM) coupled with the biosensor surface [32]. Alana and co-workers developed a cantilever-based nanobiosensor functionalized with tyrosinase to detect estrone and $\beta$-estradiol in water. These hormones were detected at ultra-low levels in water samples, and the concentration of the hormones increased the voltage suggesting the higher values of hormones. These can be useful commercially for detecting contamination of water bodies due to hospital and diagnostic laboratory wastes [33]. Another cantilever urease-based nano-biosensor was developed using graphene oxide as the base for detecting Cadmium $(\mathrm{Cd})$ in river water samples. Ultra-sensitive detection of parts per trillion (ppt) level was achieved up to a lower level of $18 \mathrm{ppt}$ [34]. A colorimetric paper-based biosensor was developed for the detection of $\mathrm{Cd}$ ions in Clams and Mussels. The sensitivity of $6 \mathrm{ppb}$ (parts per billion) was achieved. The biosensor was integrated into a paper-based format making it highly reproducible, cost-effective, and easy detection. The intensity of the color was found to be directly proportional to the levels of $\mathrm{Cd}$ ions. The integration into the paper format makes it available and robust for possible commercial usage to detect $\mathrm{Cd}$ ions in water bodies and organic waste [35].

\subsection{Single enzyme nanoparticles (SENs)} and bacterial cell surface layers (Slayers) proteins (SLPs) as potential biomaterials for the development of nano-bio sensors

In order to mitigate the issue of short catalytic shelf life of enzymes, a group of scientists at the Department of Energy's Pacific Northwest National Laboratory in Richland was able to encapsulate a single enzyme within nanomaterials. Thus, they created a new hybrid biocatalyst class known as single enzyme nanoparticles (SENs) [36]. The nanostructure's sole purpose was to act as a protective sheath for the enzyme; thus, its activity and shelf life remained uncompromised for several months. It was via this approach that they were able to stabilize two proteases (r-chymotrypsin and trypsin). Further research on SENs was carried out, and an enzyme-silicate hybrid material was obtained. These hybrid nanostructures were called single enzyme caged nanoparticles (SECNs) and consisted of self-assembled molecular-level thin silicate layers on enzymes' surfaces [37]. SEN has been utilized for biosensing applications by Yang and Zhang [38]. A piezoelectric biosensor was developed for urea detection based on SEN immobilization. Higher selective range, minimal response time, lower detection limit, and effect on stability due to nano-porous alumina were studied [38]. Yang et al. in 2013 developed an electrochemical biosensor using magnetic single enzyme nanoparticles deposited onto magnetic glassy carbon electrodes. Compared to other researchers, the biosensor showed a shorter response time of $4 \mathrm{~s}$ and a detection limit of $0.2 \mu \mathrm{M}$ [39]. Lu and co-workers developed a single-molecule enzyme nanocapsule-based biosensor for glucose detection, intending to eliminate the obstacles such as thermal stability and ultra-sensitivity. They reported the glucose oxidase-based nanobiosensor to be stable at $65^{\circ} \mathrm{C}$ temperature with an enhanced catalytic activity up to $56 \%$ [40]. SECNs retain native enzyme activity, have minor substrate diffusional limitations, and possess high stability. SECNs can also be adsorbed into mesoporous silica materials to manufacture reusable robust enzymatic systems with promising biosensors design applications. The beauty of this research over conventional immobilization methods is the individual encapsulation of enzymes within SENs. It facilitates control of the extrinsic environment where an enzyme operates and optimal substrate diffusion of an individual molecule. Moreover, enzymatic activity can often be easily fine-tuned by tailoring the polymer layer properties [41]. The development of the single enzyme nanoparticles for the usage in sensing applications has been represented in the figure (Fig. 2).

S-layer proteins (SLPs) are an intriguing biomaterial that can self-assemble on surfaces or interfaces to form two-dimensional (2D) crystalline protein 
Fig. 2 Representation of development of enzyme nanoparticles

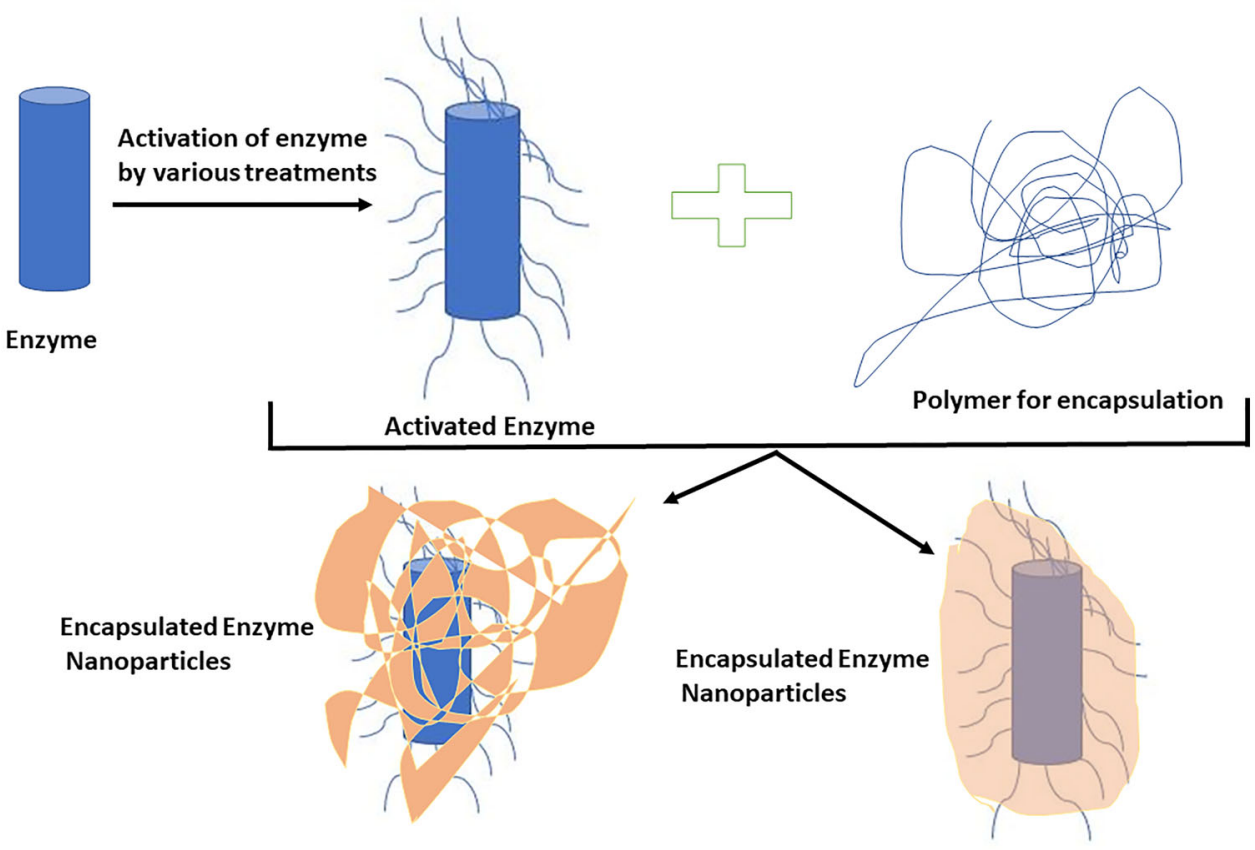

lattices. There are several critical features of S-layer proteins, which make them an ideal candidate as immobilizing biomaterial. SLPs have an ultrathin structure, are highly porous with the precise distribution of functional groups, and have antifouling characteristics [42]. These characteristics mark their suitability in the bio-fabrication of nano-biosensors. In one such study, SLP from Geobacillus stearothermophilus was exploited to develop an electrochemical sensing system. They employed recrystallized gold colloids-SLPs for the functionalization of carbon nanotubes (CNTs). The hybrid nanomaterial retained the original activity of biomolecules and maintained the mechanical and electrical properties of CNTs, thus asserting the remarkable approach for nanobiosensors design having specificity, selectivity, and sensitivity properties [43].

\section{Thermozyme-based nano-bio sensors: possibilities and gaps}

Despite holding tremendous potential, very few works that combine thermostable enzymes and nanomaterials for the fabrication of thermozymebased nano-bio sensors have been reported. Some of the notable development that has taken place in this research arena is mentioned here. Iwasa and coworkers [44] have reported the development of an electrochemical thermozyme-based nano-biosensor. They incorporated a thermozyme flavin adenine dinucleotide-dependent glucose dehydrogenase (FAD-GDH) from the thermophilic fungus Talaromyces emersonii as a biorecognition element, and single-walled carbon nanotubes (SWCNTs) attached on gold $(\mathrm{Au})$ electrode surface to create T.emersonii FAD-GDH bioanode. It was achieved by harnessing direct electron transfer between the thermozyme and the nano component. Conventionally, glucose oxidase is employed while designing glucose biosensors, but this alternative strategy employed by a thermostable, oxygen-insensitive FAD-GDH is a promising design owing to enzyme affinity, selectivity, and stability. For the nano-biosensor construction, the $\mathrm{Au}$ electrode was modified with a thin plasma-polymerized film (PPF) for the attachment of SWCNTs. Uniform attachment of SWCNTs on the electrode surface for optimum electron transfer was acquired by dispersing SWCNTs in the sodium cholate (anionic surfactant). Thermozyme immobilization on SWCNTs was carried out by electrostatic interaction, and the deposition of the PPF was done posteriorly. The $T$. emersonii FAD-GDH anode exhibited excellent stability and sensitivity, as listed in table (Table 1).

Additionally, the nano-biosensor was highly selective for glucose, and the sensing attributes were not interfered with due to the presence of ascorbic 
acid and uric acid. Thus, reflecting its potential applications in diagnostics, the food industry, the agriculture sector, and environment monitoring. However, this sensing device needs more research and advancement to be applied for real sample analysis. Researchers proposed designing an optical biosensor and detecting arsenic ion species in water. The sensing device was composed of arsenate reductase enzyme from Thermus thermophilus and was adsorbed on polyethylene glycol-stabilized gold nanospheres [45]. The enzyme-conjugated nanospheres had a hydrodynamic diameter of $39 \pm 13 \mathrm{~nm}$, forming clusters of three to four aggregated nanoparticles [27]. The thermozyme-based nano-biosensor was extraordinarily rapid and detected Arsenic species As(III) and As(V) after $10 \mathrm{~min}$ incubation with the enzyme-conjugated nanoparticles. Detection mechanism harnessed local surface plasmon resonance effect of gold nanoparticles (AuNPs) and the substantial shift upon nanoparticle exposure in different media. The shift was because of nanoparticle interactions, resulting in decreased/increased interparticle distance (i.e., aggregation or dissociation of nanoparticle clusters). The shift in local plasmon resonance was transformed into a colorimetric signal that could be directly visualized. Considering the selectivity aspects, in a previous study by the same authors, no absorbance was observed in pure solutions of $\mathrm{Cd}^{2+}, \mathrm{Pb}^{2+}$, and $\mathrm{Hg}^{2+}$ [27]. Since the selectivity mechanism was solely designed in the presence of arsenite and arsenate mixtures, the sensors could only be used for monitoring the arsenite contamination of drinking water [27, 45]. Unfortunately, this research, despite being promising, was impeded. No further tests were carried on actual water samples. Also, the selectivity aspect of nano-bio sensors concerning other potential contaminants in water was not tested.

Similarly, Liu and co-workers tried to exploit the thermozyme-nanomaterial combination for diagnostic purposes. They targeted the multifaceted pathogenesis of Alzheimer's disease (AD) by devising a smart theranostic complex consisting of gold nanorods (GNRs) loaded with thermostable acylpeptide hydrolase (APH) ST0779 specific for amyloid-beta $(\mathrm{A} \beta)$ aggregates and single-chain variable fragment 12B4 ( $s c F v$ ) collectively termed as GAS (GNRs-APH$s c F v$, GAS). The results were quite promising as the complex was rapid in detecting $A \beta$ aggregates. Additionally, the near-infra-red (NIR) photothermal treatment at high temperature disrupted the assembly of protein aggregate, at the same time enhancing $\mathrm{APH}$ activity to eliminate $\mathrm{A} \beta$ aggregates and inhibited $\mathrm{A} \beta$-mediated toxicity [46].

The striking feature of this thermozyme-based nano-biosensor is that the cascade of reactions that eliminates the protein aggregates occurs within the complex. There is no requirement for extrinsic components or steps. The theranostic complex is also highly selective because the photothermal therapy treats only those organs and tissues under light irradiation, whereas the areas in the vicinity (dark region) remain unaffected. Also, the $s c F v$-GNRs conjugate prevents non-specific heating, thus, mitigating injuries in normal tissues. This research has indeed portrayed promising output and needs further exploration. It will reduce the cost barriers patients suffer during treatment and the dependency on drugs and their side effects. Thermozymes based nano-biosensor has also been exploited for real-time monitoring and control of aldol reaction for industrial biocatalytic process. The aldol reaction, a vital carbon-carbon bond-forming reaction, forms the core of several organic synthesis for industrial applications, such as flavors, detergents, drugs, plasticizers, etc. [47]. Currently, acidic or alkaline catalysts are applied in aldol reactions. It suffers several setbacks such as intricate synthesis, environmental toxicity, stringent biocatalytic reaction conditions, and susceptibility to deactivation.

[48] have demonstrated the fabrication of enzymeconjugated gold nanorod composites (EGCs) via selfassembly approach. This approach fine-tunes and enhances the enzyme's catalytic activity, reusability, and thermal stability from mesophiles, thermophiles, and hyperthermophiles. They have also confirmed that thermozymes, in particular, are efficient for the remote-controlled nano-biocatalytic system. The nano-biocatalytic system exhibited excellent catalytic efficiency (eightfold higher), and hence 99\% yield was achieved in aldol addition within $30 \mathrm{~min}$. The remote-controlled biocatalytic systems is green technology based since it uses remote-controlled NIR stimulation to control enzyme activity, thus regulating commencement/termination of the aldol reaction and resulting in reduced energy consumption as well as cost cutoff. This marks the suitability and potential of remote-controlled nano-biocatalytic strategies in industrial applications for real-time biocatalysis. 
The researchers [49] have worked on self-assembling thermostable chimeras for arsenic biosensing in another work. They developed nano-surfaces for the immobilization of enzymes. Incorporation of two versions of a chimeric protein, namely ArsC-Vmh2 and Vmh2-ArsC, which combined the self-assembling properties of $\mathrm{Vmh} 2$, a hydrophobin from Pleurotus ostreatus, with that of TtArsC, a thermophilic arsenate reductase from Thermus thermophilus; both chimeras were heterologously expressed in Escherichia coli. The chimeric proteins immobilized on polystyrene had reusability up to three times and shelf life for 15 days with $50 \%$ activity loss. The results were promising as gold-immobilized ArsCVmh2, and Vmh2-ArsC can be exploited as electrochemical nanobiosensors for As(III) detection.

\section{Conclusion}

Despite so much research and positive outputs, the commercial biosensors available face some challenges to date. The cost factor is another issue when we talk about the fabrication of sensors. However, there are endless numbers of possibilities to create a compelling and economical nano-biosensor. Thermostable enzymes appear very promising MREs with their inherent stability in an extreme environment and need no augmentation. Their specificity, sensitivity, affinity, and activity allow the detection of analytes even in lower limits. The combination of thermozymes-nano/biohybrid material has tremendous potential, but it is still a challenging aspect to how the components' (nanomaterials and biomolecules) properties and functions can be combined into a single functional entity to maximize its output. There is a need to further explore bio-inspired smart nanosystems by using biotechnological tools such as metagenomics mining, protein engineering, site-directed mutagenesis, and new generation nanotechnological approaches for designing ultra-sensitive nano-biosensors with high reproducibility. There is a constant need to push the boundaries of research to bring the findings to real-life applications.

There could be a possibility where the combination of novel hybrid sensing elements can be implemented to mitigate the pathogenesis problem. The entire world is currently dealing with the pandemic issue where the coronavirus randomly changes or alters its polymorphic state. The use of carbon nanofibers as a nano biosensing element can be attractive because they can form an array of tiny electrodes. This dimension of tiny electrodes can be even smaller than bacteria and viruses. The use of SLPs and SENs in biosensing applications improves the robustness and versatility of nano-biosensors. The addition of thermozymes as the analytical element contributes to its stability and specificity, an issue with which a number of biosensors deal. Overall, the integration of thermozymes with nanomaterials provides us the answer to the number of limitations that biosensors have been facing related to their robustness, sensitivity, stability, and reproducibility.

\section{Acknowledgements}

The author acknowledges the Department of Biotechnology, Government of India for providing DBT-JRF fellowship to Snehi Soy, Grant No. [DBT/ 2017/IBIT-R/771]. The authors highly acknowledge Dr. Pragya Prakash for his valuable suggestions in the preparation of the manuscript.

\section{Author Contributions}

SS has contributed to the conceptualization, preparation, and editing of the manuscript; SRS has contributed to the conceptualization of the manuscript along with the editing and review of the manuscript; and VKN has contributed to the conceptualization and editing of the manuscript.

\section{Funding}

The author acknowledges the Department of Biotechnology, Government of India, for providing DBTJRF fellowship to Snehi Soy, Grant No. [DBT/2017/ IBIT-R/771].

\section{Data Availability}

Not applicable.

\section{Code availability}

Not applicable. 


\section{Declarations}

Conflict of interest The authors declare no conflict of interest.

Ethical approval Not applicable.

\section{Consent to participate Not applicable.}

Consent for publication Not applicable.

\section{References}

1. L.C. Clark Jr., C. Lyons, Ann. N. Y. Acad. Sci. 1962, 29-45 (2006). https://doi.org/10.1111/j.1749-6632.1962.tb13623.x

2. N.S. Fracchiolla, S. Artuso, A. Cortelezzi, Sensors 13, 6423-6447 (2013)

3. A. Villalonga, A.M. Pérez-Calabuig, R. Villalonga, Anal. Bioanal. Chem. 7, 1-8 (2020). https://doi.org/10.1007/s0021 6-019-02226-x

4. P. Mehrotra, J. Oral Biol. Craniofac. Res. 6, 153-159 (2016). https://doi.org/10.1016/j.jobcr.2015.12.002

5. N. Bhalla, Y. Pan, Z. Yang, A.F. Payam, ACS Nano 14, 7783-7807 (2020). https://doi.org/10.1021/acsnano.0c04421

6. M. Staiano, A. Pennacchio, A. Varriale, A. Capo, A. Majoli, C. Capacchione et al., Methods Enzymol. 589, 115-131 (2017). https://doi.org/10.1016/bs.mie.2017.01.015

7. J. Peña-Bahamonde, H.N. Nguyen, S.K. Fanourakis et al., J. Nanobiotechnol. 16, 75 (2018). https://doi.org/10.1186/s129 51-018-0400-Z

8. I.S. Kucherenko, O.O. Soldatkin, D.Y. Kucherenko, O.V. Soldatkina, S.V. Dzyadevych, Nanoscale Adv. 1, 4560-4577 (2019). https://doi.org/10.1039/C9NA00491B

9. C. Purcarea, G. Necula-Petrareanu, A. Vasilescu, in Functional Nanostructured Interfaces for Environmental and Biomedical Applications, eds. By V. Dinca and M. P. Suchea (Elsevier, 2019), pp 153-180 https://doi.org/10.1016/B978-012-814401-5.00007-4

10. V.K. Nigam, P. Shukla, J. Microbiol. Biotechnol. 25, 1773-1781 (2015). https://doi.org/10.4014/jmb.1504.04010

11. S. D'Auria, J.R. Lakowicz, Curr. Opin. Biotech. 12, 99-104 (2001). https://doi.org/10.1016/s0958-1669(00)00164-6

12. F. Rigoldi, S. Donini, A. Redaelli, E. Parisini, A. Gautieri, APL Bioeng. 2, 011501 (2018). https://doi.org/10.1063/1. 4997367

13. A. Bala, B. Singh, Renew. Energy 136, 1231-1244 (2019). h ttps://doi.org/10.1016/j.renene.2018.09.100

14. S. Soy, V.K. Nigam, S.R. Sharma, J. Biosci. 44, 124 (2019). h ttps://doi.org/10.1007/s12038-019-9938-7
15. S. Sharma, S. Vaid, B. Bhat, S. Singh , B.K. Bajaj, in Advances in Enzyme Technology, eds. By V. Dinca and M.P. Suchea (Elsevier, 2019), pp 469-495. https://doi.org/10.1016/ B978-0-444-64114-4.00017-0

16. C. Vieille, G.J. Zeikus, Microbiol. Mol. Biol. Rev. 65, 1-43 (2019). https://doi.org/10.1128/MMBR.65.1.1-43.2001

17. S. Kumar, R. Nussinov R, Cell Mol Life. Sci. 58, 1216-1233 (2001). https://doi.org/10.1007/PL00000935

18. N. Vasudevan, A. Jayshree, Encyclopedia of Marine Biotechnology 3, 1711-1736 (2020). https://doi.org/10.1002/ 9781119143802.ch72

19. S. Kumar, C.J. Tsai, R. Nussinov, Protein Eng. 13, 179-191 (2000). https://doi.org/10.1093/protein/13.3.179

20. S. Chakravarty, R. Varadarajan, FEBS Lett. 470, 65-69 (2000)

21. S. D’Auria, M. Moracci, F. Febbraio, F. Tanfani, R. Nucci, M. Rossi, Biochimie 80, 949-957 (1998). https://doi.org/10.101 6/S0300-9084(00)88892-6

22. M. Kambourova, Eng. Life Sci. 18, 758-767 (2018). https://d oi.org/10.1002/elsc.201800022

23. A. Pennacchio, V. Sannino, G. Sorrentino, M. Rossi, C.A. Raia, L. Esposito, Appl. Microbiol. Biotechnol. 97, 3949-3964 (2013). https://doi.org/10.1007/s00253-012-4273$\mathrm{Z}$

24. W. Zhang, A.M. Asiri, D. Liu, D. Du, Y. Lin, Trends. Analyt. Chem. 54, 1-10 (2014). https://doi.org/10.1016/j.trac.2013. 10.007

25. G. Gallo, R. Puopolo, D. Limauro, S. Bartolucci, G. Fiorentino, Open Biochem. J. (2018). https://doi.org/10.2174/ 1874091X01812010149

26. S. Vigneshvar, C.C. Sudhakumari, B. Senthilkumaran, H. Prakash, Front. Bioeng. Biotechnol. 4, 11 (2016). https://doi. org/10.3389/fbioe.2016.00011

27. J. Politi, J. Spadavecchia, G. Fiorentino, I. Antonucci, S. Casale, L. De Stefano, Nanotechnology 26, 435703 (2015). h ttps://doi.org/10.1088/0957-4484/26/43/435703

28. S.A. Ansari, Q. Husain, Biotechnol. Adv. 30, 512-523 (2012). https://doi.org/10.1016/j.biotechadv.2011.09.005

29. J. Cruz, K. Würges, M. Kramer, P. Pfromm, M. Rezac, P. Czermak, in Nanoscale Biocatalysis, Methods in Molecular Biology, ed. By P. Wang (Humana Press, 2011), pp 147- 160. doi: https://doi.org/10.1007/978-1-61779-132-1 12.

30. X. Huang, Y. Zhu, E. Kianfar, J. Mater. Res. Technol. 12, 1649-1672 (2021). https://doi.org/10.1016/j.jmrt.2021.03. 048

31. H.P. Lang, M. Hegner, C. Gerber, Mat. Tod 8, 30-36 (2005). https://doi.org/10.1016/S1369-7021(05)00792-3

32. A.A. Rigo, A.M. Cezaro, D.K. Muenchen, J. Martinazzo, A.N. Brezolin, L. Hoehne, J. Steffens, C. Steffens, Braz. 
J. Chem. Eng. 36, 1429-1437 (2020). https://doi.org/10.1590/ 0104-6632.20190364s20190035

33. M. de Cezaro, A.A. Rigo, J. Martinazzo, D.K. Muenchen, A. Manzoli, D.S. Correa, J. Steffens, C. Steffens, Appl. Biochem. Biotechnol. 190(4), 1512-1524 (2020). https://doi.org/ 10.1007/s12010-019-03195-8

34. S.C. Ballen, G.M. Ostrowski, J. Steffens, C. Steffens, IEEE Sens. J. 21(8), 9626-9633 (2021). https://doi.org/10.1109/JS EN.2021.3056042

35. K.K. Swain, S. Bhand, Anal. Bioanal. Chem. 413(6), 1715-1727 (2021). https://doi.org/10.1007/s00216-020-0314 $0-3$

36. J. Kim, J.W. Grate, Nano Lett 3, 1219-1222 (2003). https://d oi.org/10.1021/n1034404b

37. S.G. Hong, B.C. Kim, H.B. Na, J. Lee, J. Youn, S.W. Chung et al., Chem. Eng. J. 322, 510-515 (2017). https://doi.org/10. 1016/j.cej.2017.04.022

38. Z. Yang, C. Zhang, Sens. Actuators B Chem. 188, 313-317 (2013). https://doi.org/10.1016/j.snb.2013.07.004

39. Z. Yang, C. Zhang, J. Zhang, L. Huang, Electrochim. Acta 111, 25-30 (2013). https://doi.org/10.1016/j.electacta.2013.0 8.009

40. L.X. Dhanjai, L. Wu, J. Chen, Y. Lu, Anal. Chem. 92, 5830-5837 (2020). https://doi.org/10.1021/acs.analchem.9b 05466

41. R. Chapman, M.H. Stenzel, J. Am. Chem. Soc. 141, 2754-2769 (2019). https://doi.org/10.1021/jacs.8b10338

42. Schuster, Biosensors 8, 40 (2018) doi: https://doi.org/10.339 0/bios 8020040

43. T.J. Park, S.J. Lee, J.P. Park, M.H. Yang, J.H. Choi, S.Y. Lee, J. Nanosci. Nanotechnol. 11, 402-407 (2011). https://doi.org/ 10.1166/jnn.2011.3264 (PMID: 21446464)

44. H. Iwasa, A. Hiratsuka, K. Yokoyama, H. Uzawa, K. Orihara, H. Muguruma, ACS Omega 2, 1660-1665 (2017). https://doi. org/10.1021/acsomega.7b00277

45. J. Politi, J. Spadavecchia, G. Fiorentino, I. Antonucci, L. De Stefano, J.R. Soc, Interface 13, 20160629 (2016). https://doi. org/10.1098/rsif.2016.0629

46. W. Liu, X. Li, S. Jiang, J. Bai, X. Liu, Liu et al. Theranostics 9, 2268 (2019). https://doi.org/10.7150/thno.30649

47. R. Li, B. Perez, H. Jian, M.M. Jensen, R. Gao, M. Dong, M. Glasius, Z. Guo, Appl. Microbiol. Biotechnol. 99, 9625-9634 (2015). https://doi.org/10.1007/s00253-015-6758-z

48. W. Li, D. Liu, X. Geng, Z. Li, R. Gao, Catal Sci. Technol. 9, 2221-2230 (2019). https://doi.org/10.1039/c9cy00167k

49. R. Puopolo, I. Sorrentino, G. Gallo, A. Piscitelli, P. Giardina, A. Le Goff, G. Fiorentino, Sci. Rep. 11(1), 1-2 (2021). h ttps://doi.org/10.1038/s41598-021-82648-9

50. P. Bollella, L. Gorton, R. Ludwig, R. Antiochia, Sensors 17, 1912 (2017). https://doi.org/10.3390/s17081912
51. S. D’Auria, N. Di Cesare, Z. Gryczynski, I. Gryczynski, M. Rossi, J.R. Lakowicz, Biochem. Biophys. Res. Commun. 274, 727-731 (2000). https://doi.org/10.1006/bbrc.2000.3172

52. R.B. Iyer, J. Wang, L.G. Bachas, Extremophiles 6, 283-289 (2002). https://doi.org/10.1007/s00792-001-0255-2

53. R. Iyer, V. Pavlov, I. Katakis, L.G. Bachas, Anal. Chem. 75, 3898-3901 (2003). https://doi.org/10.1021/ac0262980

54. M. Koblížek, J. Malý, J. Masojídek, J. Komenda, T. Kučera, M.T. Giardi et al., Biotechnol. Bioeng. 78, 110-116 (2002). h ttps://doi.org/10.1002/bit.10190

55. M. Özkan, E. Erhan, Ö. Terzi, I. Tan, ŞK. Özöner, Talanta 79, 1412-1417 (2009). https://doi.org/10.1016/j.talanta.2009.06.012

56. J. Li, J. Wang, L.G. Bachas, Anal. Chem. 74, 3336-3341 (2002). https://doi.org/10.1021/ac015653s

57. R. Pieters, S.P. Hunger, J. Boos, C. Rizzari, L. Silverman, A. Baruchel et al., Cancer 117, 238-249 (2011). https://doi.org/ 10.1002/cncr.25489

58. N.E. Labrou, M.M. Muharram, Enzyme Microb. Technol. 92, 86-93 (2016). https://doi.org/10.1016/j.enzmictec.2016.06.013

59. Y. Tani, Y. Itoyama, K. Nishi, C. Wada, Y. Shoda, T. Satomura et al., Anal. Sci. 25, 919-923 (2009). https://doi.org/10. 2116/analsci.25.919

60. D. Del Giudice, E. Limauro, S. Pedone, G. Bartolucci, Fiorentino. Biochim. Biophys. Acta 1834, 2071-2079 (2013). h ttps://doi.org/10.1016/j.bbapap.2013.06.007

61. K. Ozawa, H. Iwasa, N. Sasaki, N. Kinoshita, A. Hiratsuka, K. Yokoyama, Appl. Microbiol. Biotechnol. 101, 173-183 (2017). https://doi.org/10.1007/s00253-016-7754-7

62. A. Mukhopadhyay, A.K. Dasgupta, K. Chakrabarti, Biores. Technol. 179, 573-584 (2015). https://doi.org/10.1016/j.bior tech.2014.12.070

63. M.D. Blankschien, L.A. Pretzer, R. Huschka, N.J. Halas, R. Gonzalez, M. S. Wong Acs. NANO 7, 654-663 (2013). h ttps://doi.org/10.1021/nn3048445

64. N. Dutta, A. Mukhopadhyay, A.K. Dasgupta, K. Chakrabarti, PLoS ONE 8, e63567 (2013). https://doi.org/10.1371/journal. pone. 0063567

65. N.A. Samak, Y. Tan, K. Sui, T.T. Xia, K. Wang, C. Guo et al., Mol. Catal. 445, 269-278 (2018). https://doi.org/10.1016/j. mcat.2017.12.004

66. A. De Poulpiquet, A. Ciaccafava, R. Gadiou, S. Gounel, M.T. Giudici-Orticoni, N. Mano et al., Electrochem. Commun. 42, 72-74 (2014). https://doi.org/10.1016/j.elecom.2014.02.012

67. S. Holmberg, M. Rodriguez-Delgado, R.D. Milton, N. Ornelas-Soto, S.D. Minteer, R. Parra et al., ACS Catal. 5, 7507-7518 (2015). https://doi.org/10.1021/acscatal.5b01600

Publisher's Note Springer Nature remains neutral with regard to jurisdictional claims in published maps and institutional affiliations. 